\title{
O uso das tecnologias no ensino fundamental: novos desafios para o professor de educação física em uma escola pública de Goiânia
}

\author{
Ana Maria da Conceição Silva* \\ Matilde Gonçalves da Penha**
}

\begin{abstract}
Resumo
As tecnologias fazem parte do cotidiano, especialmente das crianças e adolescentes que nasceram em meio a elas. São eles os estudantes do Ensino Fundamental, jovens que não concebem o mundo sem a existência desses recursos. A televisão, o vídeo game, o celular, o computador e a Internet podem ser considerados os principais exemplos. A Internet apresenta fascinantes atrativos como salas de bate-papo, redes sociais, e-mails e blogs pessoais. Como as tecnologias são trabalhadas no contexto escolar? O objetivo desta pesquisa foi verificar se os professores de Educação Física utilizam as tecnologias nas aulas do Ensino Fundamental. A Educação Física é uma disciplina concebida tradicionalmente como prática, visando à promoção da saúde através de esportes, jogos, ginástica e lutas. Foi feita uma pesquisa de campo com professores e estudantes do Ensino Fundamental, com a aplicação de um questionário diferente para cada grupo. A conclusão é de que os professores de Educação Física, assim como os outros, precisam entender melhor as finalidades das tecnologias na Educação, para bem utilizá-las.
\end{abstract}

Palavras-chave: educação física, tecnologia, ensino fundamental.

The use of technology in elementary education: new challenges for PE teachers in public schools in Goiânia

\begin{abstract}
Technology is part of everyday life, especially of children and teens, who are born to it. These young students of elementary schools cannot conceive of a world without such resources. The television, video games, cell phones, computers and the Internet are the principal examples. The Internet provides fascinating attractions such as chat rooms, social networks, e-mails and personal blogs. How are these technologies treated in the school context? The aim of this research was to see if Physical Education (PE) teachers use them in Elementary education classes. PE is a practical subject which encourages healthy practices by means of sports, games, gymnastics and wrestling. A field research was carried out among elementary school PE teachers and students in which a different questionnaire was given to each group.

* Professora de Biologia do Cepae/UFG. E-mail: anmaconsil@gmail.com

** Graduada em Educação Física e professora do curso de especialização Saúde Pública e Estratégia de Saúde da Família, Fisiologia do Exercício e Prescrição de Atividade Física e Enfermagem em Urgência e Emergência, da UniEvangélica. E-mail: matildepenha@yahoo.com.br
\end{abstract}


It was concluded that PE teachers and others must improve their understanding of the aims of technology in Education in order to make better use of it.

Keywords: physical education (PE), technology, elementary education.

\section{Introdução}

A revolução tecnológica provocou mudanças no modo de viver das pessoas e a sociedade sofreu mudanças de forma acelerada. A educaçáo, apesar de não responder aos avanços na mesma rapidez, aos poucos tende a se adequar a essa nova situação.

As disciplinas do Ensino Fundamental, neste estudo em especial a Educação Física, devem adequar-se para trabalhar com as novas tecnologias no processo de ensino e aprendizagem, visando a uma maior proximidade à realidade dos estudantes.

A Educação Física, disciplina obrigatória no currículo da Educação Básica, historicamente sempre foi concebida como eminentemente prática. Em certos períodos foi instrumento ideológico do Estado, servindo para adestrar a população, para preparar para a guerra e para descobrir atletas Olímpicos (BRACHT, 1997).

Após as teorias críticas da educação, também a Educação Física escolar incorporou novos significados passando não somente a preparar o corpo do estudante, mas a ampliar sua visão crítica da sociedade em que vive. Cabe então perguntar: essa mesma Educaçấo Física que se abriu para preparar além do físico também o cognitivo, está apta a trabalhar com as novas tecnologias?

O objetivo deste trabalho foi buscar respostas para esta questão, verificando se os professores de Educação Física de uma escola de Ensino Fundamental da Rede Pública de Goiânia utilizam as tecnologias em suas aulas.

\section{Tecnologias na educaçáo}

Que tipo de educação se deve dar aos estudantes? Como educá-los para compreenderem as novas tecnologias e sua forma de interação com a sociedade? Como elas interferem na formação do sujeito? São muitas as perguntas que surgem juntamente com tantos recursos tecnológicos que encantam e desafiam os educadores. 
Historicamente, a entrada das tecnologias na educação brasileira ocorreu a partir da década de 1960, fato que provocou certo preconceito no meio educativo. A ideia então dominante era de que o país procurava se inserir no mercado global não só como produtor de bens, mas também como consumidor. Ou seja, as tecnologias estavam associadas ao desenvolvimento econômico mundial (LEITE et al. 2009).

$\mathrm{Na}$ educação essa invasão tecnológica deu origem ao modelo tecnicista que foi preconizado como proposta de "modernização da prática pedagógica e solução de todos os seus problemas" (LEITE et al. 2009, p. 14). Nesse contexto surge uma área denominada Tecnologia Educacional, que dava ênfase aos meios na educação sem interrogar suas finalidades. De acordo com Leite et al. (2009), o uso das tecnologias pelas escolas associou-se a uma visão limitada de educação sob influência de teorias e ideologias externas.

A partir da década de 1980, a Tecnologia Educacional passou a ser vista como uma opçáo para se contextualizar a educação articulando os conhecimentos trabalhados com as questóes sociais, com o objetivo de desenvolver o educando de forma integral. Começa a ficar claro que apenas fazer uso das tecnologias não é suficiente, sendo necessárias também inovaçôes na prática pedagógica (LEITE et al. 2009).

De acordo com Kenski (2003), o acesso às tecnologias deve ser democratizado a partir da escola, processo que se apresenta como um desafio para a sociedade contemporânea, que precisa garantir que as informaçóes estejam acessíveis a todos por meio da utilização das novas tecnologias. Assim, "abrirse para as novas educaçóes - resultantes de mudanças estruturais nas formas de ensinar e aprender possibilitadas pela atualidade tecnológica - é o desafio a ser assumido por toda a sociedade" (KENSKI, 2003, p. 27).

As tecnologias no contexto educativo devem responder a objetivos pedagógicos, que visem à integração do estudante com os conteúdos curriculares. Os recursos tecnológicos devem permear o currículo construído no cotidiano escolar.

Leite et al. (2009) dividem as tecnologias educativas em independentes e dependentes e fazem uma conceituação e classificação das mesmas. As tecnologias independentes são caracterizadas como aquelas que não dependem de energia elétrica ou recursos eletrônicos, tanto na sua produção como na sua utilização.

O presente trabalho focalizou as tecnologias dependentes que são aquelas que dependem de um ou mais recursos elétricos ou eletrônicos para 
a sua produção ou utilização. São elas: Ambientes Virtuais de Aprendizagem (AVA); audioconferência (conference call); blog; chat ou bate-papo; correio eletrônico; computador; Comunidades Virtuais de Aprendizagem (CVA); DVD; FAQs (Frequently Asked Questions); fórum de discussão; Internet e suas ferramentas; lista de discussão; quadro interativo ou quadro eletrônico; mídia sonora; página (home Page) instrucional; podcasting; palmtops, PDAs e Hand Helds; programas de computador; rádio; site; slide; televisão comercial; televisão educativa; transparência para retroprojetor; vídeo; videoconferência; webquest e wiki (Leite et al. 2009).

As tecnologias apresentadas compóem um rol de possibilidades que os professores das diferentes disciplinas podem utilizar como ferramentas para alcançar seus objetivos educacionais. Muitos dos recursos pedagógicos acima apresentados são pouco utilizados e outros se apresentam apenas no contexto das escolas particulares.

\section{O ensino fundamental}

Integrante da Educação Básica, o Ensino Fundamental, com duração de nove anos, é a segunda etapa na educação escolar dos jovens, de cumprimento obrigatório de acordo com a Lei de Diretrizes e Bases da Educação Nacional, Lei n. 9.394/96. Esta etapa tem por objetivo a formação básica do cidadáo, que deve ser alcançada mediante domínio da leitura, escrita e cálculo; compreensão dos ambientes natural e social, político, tecnológico, artístico e valores fundamentais da vida em sociedade, compreendendo desde vínculos familiares até laços de solidariedade humana (Brasil, 1996).

O currículo deve ter uma base nacional comum a ser complementada com a parte diversificada, que deve incluir temas pertinentes à sociedade local (Brasil, 2001). Assim, as escolas devem organizar seus currículos integrando contexto local, regional e global. Os estudantes aprendem os conhecimentos e valores explícitos nas diretrizes nacionais, que somados à parte diversificada visam a construir sua identidade para torná-los responsáveis por suas açóes, solidários e com autonomia sobre sua trajetória.

Os estudantes que cursam o ensino fundamental estáo recebendo denominaçôes para diferenciá-los dos adultos, sendo chamados de "nativos digitais" (PRENSKY, 2001), homo zappiens (VEEN; VRAKKING, 2009), "cabeças digitais", "leitor imersivo" (TOSCHI, 2010) dentre outras denominaçóes dadas por diferentes teóricos da área. Esta forma de nomeá-los 
parte do princípio de que são diferentes dos estudantes que tradicionalmente chegavam à escola e visa caracterizar essas diferenças.

$\mathrm{O}$ atual estudante está crescendo em meio à tecnologia digital e gasta seu tempo com jogos de computadores e vídeogame, assistindo TV e usando celulares. Durante o período escolar que abrange infância e adolescência, os estudantes passam cerca de dez mil horas jogando videogame, vinte mil horas assistindo TV, sem contar as horas nas salas de bate-papo disponíveis na Internet, ao passo que passam em média apenas cinco mil horas lendo e estudando (PRENSKY, 2001).

Prensky (2001) afirma que nossos estudantes são "nativos falantes" da era dos computadores, isto é, são nativos digitais. Segundo este autor as pessoas que nasceram depois do advento do computador tem maior facilidade de trabalhar com eles, pois convivem desde a infância com essas máquinas e as concebem como algo comum e indispensável.

Os estudantes aprendem ouvindo música, jogando, papeando no MSN, dentre outras formas peculiares da idade. Como acompanhálos? Segundo Prensky (2001), os professores de hoje têm que aprender a se comunicar usando a linguagem e o estilo dos estudantes. $\mathrm{O}$ que náo significa mudarem o que pensam e o que são, mas sim, buscarem mais rapidez, andando lado a lado com esses nativos digitais.

O comportamento e o pensamento do homo zappiens é influenciado pelas tecnologias; as informaçóes e as pessoas de que precisam estão apenas a um clique de distância. Essa nova geração aprende desde cedo que existem diversas fontes de informaçóes e aprendem a organizar seus amigos em redes com os quais se comunicam frequentemente através da Internet (VEEN; VRAKKING, 2009).

Essa geração tem necessidade de ter o controle da situação, o que pode ser observado nos jogos no pátio da escola. Os homo zappiens não gostam de participar de jogos com regras fixas, preferem seus próprios jogos e suas regras, que muitas vezes não têm ganhadores ou perdedores. "As regras do jogo podem ser mudadas, e aí está a graça. Assim o jogo passa a ser um evento social em evolução, dirigido pelos próprios jogadores" (VEEN; VRAKKING, 2009, p. 40).

\section{Educação física e tecnologia}

Esta pesquisa aborda a Educação Física como componente curricular da Educação Básica, embora possa parecer incoerente atrelar novas tecno- 
logias com os conteúdos tratados na Educação Física, que abarca jogos, lutas, esportes, ginástica, atividades rítmicas (SOARES et al, 1992). Esses conteúdos são trabalhados ao longo das séries com diferentes tratamentos nos quais os estudantes experimentam, vivenciam, organizam informaçóes e são levados a refletir sobre a ação.

No mundo atual é necessário que os profissionais se formem academicamente e profissionalmente "com as novas tecnologias e os avanços científicos, ou seja, [que se instruam] na informática e telemática que a sociedade maneja como ferramenta cotidiana" (SEBRIAM, 2009, p. 43), o que exige da Educação Física um repensar de suas metas, objetivos e didática.

As relaçôes atuais entre Educação Física e tecnologia se centralizam na consideração de que a tecnologia é um recurso imprescindível na formação e no trabalho dos professores e também como um recurso para ser utilizado no exercício da docência (CAPLLONCH, 2005, 2007; ROMERO, 2007 apud SEBRIAM, 2009).

Como em outras disciplinas escolares a utilização das tecnologias depende do grau de conhecimento do professor. De acordo com Sanches e Romance (2002 apud Sebriam, 2009), existem três classificaçóes para o uso da informática pelos docentes de Educação Física: o uso aleatório da informática; o uso de softwares específicos da área; e o uso da Internet.

Capllonch (2007 apud Sebriam, 2009, p. 66) considera que

[...] em nenhum caso a tecnologia deve roubar o espaço da atividade motora ou, ainda, converter-se em uma alternativa para os dias de chuva, ou quando não se dispóe de uma instalação. $\mathrm{Na}$ visão da pesquisadora, é obrigação e responsabilidade dos professores introduzir estes novos recursos para favorecer os processos de ensino e aprendizagem dos alunos, assim como, modelos formativos inovadores que se adequem à maneira de aprender e às necessidades e tendências dos estudantes atuais; entretanto, não somente desde uma perspectiva técnica, mas também crítica, que implique os próprios recursos como objeto de estudo.

As tecnologias, se utilizadas dentro dos objetivos da Educação Física escolar, podem ser um atrativo a mais para os estudantes. Por ser uma disciplina eminentemente prática que em geral conquista a maioria dos alunos, se atrelada às tecnologias pode ter um alcance pedagógico ainda maior. Os processos educativos estão em evoluçáo, os alunos já não são mais os mesmos, têm formas de aprender e pensar diferentes; assim, é necessário mudar o jeito de ensinar. 
São poucas as publicaçóes sobre as iniciativas de inserção das tecnologias na Educação Física escolar. A revista Nova Escola (2009) sugere a Internet e o vídeo como importantes recursos tecnológicos para essa disciplina. As práticas corporais podem ser trabalhadas também através de apreciação.

Segundo Neira, professor universitário citado na reportagem, existem esportes que são impossíveis de ser praticados na escola, dos quais cita canoagem e paraglider que poderiam ser trabalhados de modo virtual. Podese utilizar vídeos também para desmistificar preconceitos culturais, tais como a ideia de violência dos jogos de futebol americano, que, quando analisados em detalhe, revelam a riqueza dos esquemas táticos e sua sofisticação (POLATO, 2009).

Neira (apud POLATO, 2009) também ressalta que os vídeos não servem só para apreciação, podendo os alunos produzirem seus próprios vídeos, a partir de apresentaçóes de dança por exemplo, ou de partidas de diferentes esportes. Esse procedimento permite que os alunos avaliem a própria prática.

Construir uma nova didática, que contemple prática e tecnologia, concebida como auxiliar na construçáo do conhecimento a partir da teoria, favorece a formação de cidadáos saudáveis e críticos ao mesmo tempo.

\section{A pesquisa}

Em busca de respostas ao objetivo deste trabalho, realizou-se uma pesquisa de campo, quanti-qualitativa, com aplicação de questionários a oitenta estudantes e quatro professores de uma escola pública de Ensino Fundamental de Goiânia. O questionário respondido pelos alunos apresenta nove questôes objetivas; o dos professores é misto, com questôes objetivas e discursivas, num total de sete. Os alunos que responderam ao questionário cursavam entre o $4^{\circ}$ e o $9^{\circ}$ ano. Os professores foram denominados Professor 1, Professor 2, Professor 3 e Professor 4, para facilitar a apresentação e a discussão dos resultados.

A escola pesquisada, de regime integral, possui todas as séries do Ensino Fundamental (420 alunos) e atende estudantes da região onde está localizada e de regióes circunvizinhas.

Responderam ao questionário $14 \%$ dos alunos do quarto ano; $28 \%$ do quinto ano; $8 \%$ do sexto ano; $14 \%$ do sétimo; $20 \%$ do oitavo ano; e $16 \%$ do nono ano. As séries que tiveram maior participação dos alunos ao 
responder o questionário foram o quinto e o oitavo anos. Os alunos foram escolhidos de forma aleatória conforme disponibilidade deles na escola. Dos estudantes pesquisados $68 \%$ eram do sexo feminino e $32 \%$ do sexo masculino. As idades dos alunos variaram entre 10 e 17 anos.

\section{Resultados e discussão}

O questionário dos estudantes iniciou-se com uma pergunta básica: se utilizavam a Internet. Todos os estudantes responderam que sim, afinal são nativos da era dos computadores, aprendem, pesquisam e se comunicam através da rede (PRENSKY, 2001; VEEN; VRAKKING, 2009), num mundo sem fronteiras cuja Internet interpola a noçâo de limite territorial.

A segunda pergunta questiona sobre o local de uso da Internet: $32 \%$ dos alunos disseram possuir em suas casas; $29 \%$ utilizam na escola; $28 \%$ fazem uso dela em lan houses; e 11\% marcaram a opção outros, que pode se referir a casa de parentes e amigos. É fato que as crianças e adolescentes são os mais interessados no computador com Internet, principalmente para diversão e comunicação (VEEN; VRAKKING, 2009). A escola entra como mediadora do processo, levando os estudantes a perceber as diversas possibilidades da rede e como bem utilizá-las.

A terceira questão interroga se a escola possui Laboratório de Informática (LI) com Internet. A Internet oferecida na escola possibilita àqueles que ainda não a possuem em casa ter acesso a essa tecnologia. Os LI possibilitam não só a inclusão digital, mas também a inclusão social de muitos estudantes de escolas periféricas.

O computador está presente na maioria das escolas do estado e do país e esta é a mídia que mais seduz os jovens. Dessa forma não se pode ignorar sua contribuição no processo de ensino e aprendizagem e, mais, que "as possibilidades de busca de informação utilizando o computador, por meio da Internet, podem ser incomensuráveis" (ROSA, 2010, p. 67).

A quarta questáo pergunta se os estudantes participavam de redes sociais, tais como Orkut, Facebook, Twitter. Dos estudantes pesquisados $94 \%$ participam, e apenas $6 \%$ não. Os adolescentes é que mais participam desses ambientes, seduzidos pelas possibilidades de comunicação e interação em tempo real com outras pessoas de diversas localidades. Independente do local onde estáo, interagem com um simples clique no mouse de um computador conectado à rede mundial. 
O quinto questionamento foi se os estudantes tinham o hábito de participar de bate-papos on-line, e as respostas obtidas mostraram que 80\% dos alunos participam. Conforme Masetto (2000), o computador e suas infinitas possibilidades contribuem para o desenvolvimento dos estudantes, garantindo-lhes a possibilidade de trabalhar numa dimensão lúdica, não linear, com grande possibilidade criativa e exploratória, o que ajuda na construção do conhecimento e na forma de expressar.

A sexta pergunta questiona se os alunos gostavam das aulas de Educação Física. Verificou-se que apenas $4 \%$ dos estudantes pesquisados não gostavam das aulas, e $96 \%$ disseram gostar dessas aulas.

A pertinência desta pergunta reside no fato de que muitas crianças e adolescentes não gostam das aulas de Educação Física ou simplesmente se recusam a fazer determinadas atividades propostas. Em geral, "o receio ou a vergonha do aluno em correr riscos de segurança física é motivo suficiente para que ele se negue a participar de uma atividade" (BRASIL, 2001, p. 37).

Existem vários fatores internos e externos para a não aceitação dessa disciplina entre os quais destacam-se os riscos para a segurança física que determinados exercícios oferecem; o grau de excitaçáo somática individual; as vivências anteriores dos estudantes e suas características individuais; e a forma como o aluno se expóe nessas aulas (BRASIL, 2001).

$\mathrm{O}$ uso de tecnologias no contexto da Educação Física escolar pode proporcionar maior convencimento a esses educandos que se negam a participar das atividades com bolas, cordas e outros materiais, por medo, vergonha ou qualquer outro motivo pessoal.

$\mathrm{Na}$ sétima questão elencaram-se alguns itens para que os alunos marcassem quais já foram utilizados pelos professores de Educação Física; poderiam marcar mais de uma resposta, fato que levará a um total maior que $100 \%$. De acordo com as respostas, $32 \%$ dos estudantes disseram que os professores utilizam vídeos em suas aulas e 36\%, a TV. O aparelho de som foi marcado por $27 \%$ dos alunos. E $9 \%$ disseram que já utilizaram o projetor de imagens (data show). O computador foi assinalado por $8 \%$ e a Internet por $7 \%$.

Segundo Betti (apud BIANCHI, 2008) "com a expansão tecnológica, o jogo não é apenas aquele jogo simples, jogado num terreno qualquer, por crianças, é também videogame, espetáculo da televisáo" entre outros. Descortina-se um novo cenário ao qual a Educação Física deve se adequar. 
A oitava questáo pergunta sobre a importância do uso dos recursos tecnológicos como auxiliares nas aulas de Educação Física; 70\% dos estudantes disseram que é importante, enquanto 30\% disseram não. É possível que esses 30\% tenham sua concepção de aula de Educaçáo Física fundamentada na perspectiva do movimento corporal, sem compreensão crítica de seu papel (DARIDO; RANGEL, 2005). Cabe aos professores orientarem e informarem seus alunos sobre o que é essa disciplina, suas finalidades e as diferentes formas de trabalho.

"A Educação Física hoje contempla múltiplos conhecimentos produzidos e usufruídos pela sociedade a respeito do corpo e do movimento" (BRASIL, 2001, p. 27). A partir das manifestaçóes existentes (jogo, esporte, dança, ginástica, lutas), o professor deve expor seus benefícios fisiológicos e psicológicos "e suas possibilidades de utilização como instrumento de comunicação, expressão, lazer e cultura, e formular a partir daí as propostas para a Educaçáo Física escolar" (BRASIL, 2001, p. 27).

$\mathrm{Na}$ construção dos conhecimentos próprios da disciplina podem-se utilizar vários recursos tecnológicos sem desmerecer ou deixar de abranger seu caráter de prático. Os alunos que dáo importância a esses recursos (70\%), possivelmente já entenderam que a Educação Física tem um conteúdo a ser apreendido além de reproduzir movimentos corporais.

A última pergunta questiona aos alunos qual o tipo de aula que facilita o aprendizado. De acordo com as respostas, $52 \%$ dos alunos apontaram as aulas práticas; em seguida vem o uso das tecnologias com 39\% das respostas; apenas $9 \%$ dos alunos apontam as aulas teóricas.

$\hat{E}$ interessante ressaltar que as tecnologias não devem roubar o espaço da atividade motora. O professor deve introduzir estes recursos, de forma planejada, para favorecer os processos de ensino e aprendizagem dos estudantes, não apenas numa perspectiva técnica, mas sim crítica (CAPLLOCH, 2007 apud SEBRIAM, 2009).

Dos quatro professores pesquisados, dois são do sexo feminino e dois do masculino, possuindo entre 35 e 50 anos. Graduados entre 1985 e 1998, todos possuem cursos de especialização.

Iniciou-se o questionário dos professores perguntando-lhes se acreditam na importância da inserção das tecnologias nas aulas de Educação Física escolar para o Ensino Fundamental. Os professores disseram que sim, e justificam esse uso como fator de enriquecimento das aulas, melhoria nos instrumentos didático-pedagógicos. 
A Educação Física está passando por uma crise paradigmática, bem mais profunda que a da década de 1980. De acordo com Da Costa (1999 apud ZOBOLI e SILVA, 2010, p. 112), a crise desta disciplina é sociocultural, ou seja, resulta do "descompasso entre a inovação tecnológica e o conhecimento profissional, que cria uma oposiçáo entre a demanda social de profissionais atualizados e a formação pouco renovada destes profissionais".

As reflexôes acerca das tecnologias na Educação Física podem ser ainda aprofundadas. Segundo Zoboli e Silva (2010, p. 112-113), no final do século XX o corpo em movimento foi o alvo das reflexões, mas, hoje o que se tem é que esses corpos não querem mais se movimentar nas quadras descobertas ao sim de gritos e apitos. As revoluçóes culturais, econômicas e sociais que são denominadas promotoras da cibercultura, levantaram questionamentos ao funcionamento clássico da Educação Física, por exemplo, com os jogos eletrônicos que transferem os movimentos musculares para a realidade virtual. Os ciberatletas transferem os movimentos do próprio corpo que poderiam ser realizados no esporte para "movimentos limitados à habilidade da coordenação motora fina na operação do joystick que envolvem no máximo a coordenação óculo-manual".

O segundo questionamento aos professores é se consideram as preferências dos estudantes ao elaborarem os Planos de Ensino. Todos disseram que sim e acrescentaram que fazem uma pesquisa no início do ano e, ao elaborar o plano, verificam o que é adaptável à realidade da escola. Plano de Ensino ou Projeto de Ensino é a sistematização do trabalho do professor em determinada disciplina de acordo com uma realidade (VASCONCELOS, 2004).

A terceira questão perguntou se os mesmos utilizavam tecnologias para auxiliar no processo de ensino e aprendizagem. Todos responderam afirmativamente. E quanto às tecnologias utilizadas, os professores 1 e 2 citaram DVD, data show e celular. Os professores 3 e 4 responderam que as tecnologias utilizadas são pesquisas sobre regras e técnicas do futsal.

Partindo das respostas dos professores fica subentendido o uso das tecnologias pelos professores 3 e 4, podendo o Laboratório de Informática e os recursos oferecidos pela Internet terem sido utilizados nas pesquisas sobre regras e técnicas do futsal. Percebe-se um desentendimento em relação ao termo "tecnologia". Para o uso do DVD deve ter sido usada conjuntamente a TV, porém os professores não explicitam como foram utilizados tais recursos. 
Já faz algum tempo que as escolas vem implantando Laboratórios de Informática com redes de Internet com a finalidade de promoverem mudanças na educaçáo. A informatização, que tem acontecido cada vez mais rápido, oferece à população melhores condiçóes de sobrevivência e novas formas de se relacionar social e culturalmente no contexto global (RESENDE; PRADO; SOUZA, 2010, p. 158). "Trata-se de um tempo em que as pessoas estão se acostumando a uma rede que tem como papel principal tornar mais atraente a veiculação de informação e facilitar o acesso a grandes volumes de dados" (2010, p. 158).

Pergunta-se, na quarta questão, se os professores fizeram uso das Tecnologias de Informação e Comunicação para a execução de algum projeto educativo no Ensino Fundamental. Todos os professores pesquisados disseram já ter utilizado, sendo que os professores 1 e 2 realizaram projetos com todas as turmas, e os professores 3 e 4 apenas com os últimos anos do Ensino Fundamental.

A quinta questáo pergunta quais os resultados obtidos pelos professores com o uso das Tecnologias de Informação e Comunicação na execução desses projetos. Todos consideraram os resultados positivos, mas não citaram suas experiências de modo concreto.

A integração das TICs nas aulas de Educação Física só será possível de forma efetiva quando todo o corpo docente das escolas estiver preparado para fazer uso das mesmas, na prática pedagógica. E isso só será possível se acontecer uma preparação adequada (SEBRIAM, 2009).

Para uma utilização consciente das tecnologias é necessário que haja uma formaçáo adequada, que contribua para melhorar tanto a competência como as habilidades dos professores diante das tecnologias (BUSH, 2004 apud SEBRIAM, 2009). Atrelar disciplinas eminentemente práticas com as tecnologias é uma forma a mais de garantir que o conhecimento chegue a todos, por igual.

A sexta questão perguntou se os professores conheciam o termo "nativos digitais", ou outros termos que designem as novas geraçóes. Apenas os professores 1 e 2 disseram conhecer os termos. Os mesmos professores que desconhecem o termo "nativos digitais" são os que sentem certa dificuldade em trabalhar com o computador na sua prática pedagógica.

A sétima pergunta questiona se o modo de aprender dos estudantes do Ensino Fundamental mudou nos últimos anos. Todos disseram que sim; porém as justificativas revelaram divergências de opinião. Os pro- 
fessores acreditam que os interesses dos alunos centram-se em temas como violência, sexualidade, drogas, que são temas pertinentes à idade e à realidade desses estudantes. Com certeza é preciso uma nova educação para esse novo estudante, com novas formas de aprender. O novo aluno tem uma velocidade maior de raciocínio, faz muitas coisas ao mesmo tempo e não consegue ficar preso muito tempo em um só assunto ou lugar. Lugar, para ele, assume sem dúvida uma nova conotação; ele pode ser virtual (VEEN; VRAKKING, 2009).

Como a Internet oferece uma infinidade de conteúdos, cabe aos professores atuarem como mediadores entre esses conteúdos e os estudantes. É importante considerar que os elementos tradicionalmente concebidos no processo de mediação do conhecimento são o aluno, o professor e o saber. É necessário, agora, reconhecer a presença da tecnologia, que permeia todos os outros elementos, e utilizá-la no processo didático-pedagógico.

\section{Consideraçóes finais}

A partir da análise dos questionários chega-se à conclusão de que há diferenças entre os professores pesquisados quanto à concepção sobre o papel das novas tecnologias no ensino de Educação Física.

A diferença entre os professores pode ter relação com a idade e seu ano de formação. $\mathrm{O}$ mais velho deles concluiu sua graduação quase dez anos antes que o segundo.

Através das respostas do questionário é impossível afirmar com certeza que os professores utilizam tecnologias para ministrar suas aulas; não houve observaçóes que comprovassem ações práticas relacionadas à forma com que utilizam os recursos e se os objetivos de ensino foram alcançados por eles. As tecnologias citadas pelos professores não condizem com as citadas pelos estudantes, restando, então, uma contradição entre os dois questionários.

O estudante do século XXI tem um perfil diferenciado, para o qual os professores e a escola ainda náo estáo preparados na sua totalidade. Como a forma clássica de se conceber a educação está tão fortemente arraigada nas tradiçôes, as alteraçôes necessárias possivelmente só vão ocorrer de forma integral quando esses nativos se tornarem professores.

Como os professores não são mais detentores do conhecimento, mas mediadores entre o conhecimento e os estudantes, é necessário que acompanhem as mudanças para não se tornarem defasados na sua função 
de ensinar. Na velocidade com que as informaçóes são transmitidas muitas vezes são eles, os alunos, que levam para a sala de aula informaçóes novas, e querem respostas rápidas para as dúvidas suscitadas.

A Educação Física é uma disciplina historicamente concebida como prática, o que já está enraizado nos alunos e em muitos professores. Nas respostas dos alunos quanto à forma de aprender, eles deixaram claro que aprendem com as aulas práticas e com o uso de recursos tecnológicos.

Os professores de Educação Física podem se considerar privilegiados, pois suas aulas eminentemente práticas conquistam muitos dos alunos, havendo de fato sucesso no processo de ensino e aprendizagem. Mas existem alunos que, por questóes pessoais (timidez, obesidade etc.) ou religiosas, se afastam das aulas práticas; esses, assim como outros estudantes, fazem parte do mundo tecnológico.

A tecnologia, associada aos conteúdos e aos conhecimentos inerentes à Educação Física, possibilitará a essa disciplina maiores resultados didáticopedagógicos, favorecendo pesquisas, produção de vídeos, conhecimento de esportes oriundos de diferentes países, dentre tantas outras possibilidades.

As tecnologias trazem benefícios para a sociedade e nela estão inseridas de forma irreversível. Visto que é direito de todos o acesso a elas, é necessária a adequação das disciplinas para trabalhar com elas; em especial a Educação Física deve ser promotora dessa inclusão tecnológica.

O tema, ainda pouco explorado, merece atençáo por parte dos professores e, em especial, dos de Educação Física. É necessário novas concepções de ensino adequadas ao estudante digital. Novas experiências na área devem ser tornadas públicas, tanto os sucessos como os insucessos, pois é através da troca de experiências que o ensino pode sofrer mudanças positivas.

Espera-se que este trabalho, que pesquisou apenas uma escola, sirva de inspiração para pesquisas futuras, na busca incessante de novos conhecimentos que forneçam respostas à Educação Física contemporânea.

\section{Referências}

BIANCHI, P. A presença das tecnologias de informação e comunicação na Educação Física permeada pelo discurso da indústria cultural. EFdeportes, Revista Digital. Buenos Aires, n. 120, maio 2008. Disponível em: <http:// www.efdeportes.com/efd120/tecnologias-de-informacao-e-comunicacaona-educacao-fisica.htm>. Acesso em: 15 jan. 2011. 
BRACHT, V. Educação fisica e aprendizagem social. 2. ed. Porto Alegre: Magister, 1997. 122 p.

BRASIL, Ministério de Educação e do Desporto. Lei de Diretrizes e Bases da Educação Nacional. Brasília: MEC, 1996.

BRASIL, Ministério da Educação. Parâmetros Curriculares Nacionais: Educação Física. 3. ed. Brasília: Secretaria de Ensino Fundamental, 2001.

DARIDO, S. C.; RANGEL, I. C. A. (Org.). Educação física na escola: implicaçóes para a prática pedagógica. Rio de Janeiro: Guanabara Koogan, 2005.

KENSKI, V. M. Tecnologias e ensino presencial e a distância. 3. ed. Campinas, SP: Papirus, 2003.

LEITE, L. S. et al. Tecnologia educacional: descubra suas possibilidades na sala de aula. 3. ed. Petrópolis, RJ: Vozes, 2009.

MASETTO, M. T. Mediação Pedagógica e uso da tecnologia. In: MORAN, J. M.; MASETTO, M. T.; BEHRENS, P. (Org.). Novas tecnologias e mediação pedagógica. 3. ed. Campinas, SP: Papirus, 2000. p. 133-217.

PRENSKY, M. Digital natives, digital inmigrantes. From the Horizon: NBC University Press, v. 9, n. 5. Oct. 2001. Disponível em: <http://ritla.net/ index.php?option=com_content\&task=view\&id=Intemid=136>. Acesso em: set. 2007.

RESENDE, K. M. C.; PRADO, M. C. C.; SOUZA, S. R. Leitura na tela: planejamento sequencial de conteúdos, compreensão de textos e da linguagem informatizada. In: TOSCHI, M. S. (Org.). Leitura na tela: da mesmice à inovação. Goiânia: Ed. PUC Goiás, 2010.

ROSA, I. R. O processo de leitura escolar e o uso da tecnologia. In: TOSCHI, M. S. (Org.). Leitura na tela: da mesmice à inovação. Goiânia: Ed. PUC Goiás, 2010.

SEBRIAM, D. C. da S. Utilização das tecnologias da informação e comunicação no ensino de educação física. Dissertação (Mestrado em Engenharia de Mídias para a Educação) - Faculdade de Motricidade Humana de Lisboa, Université de Poitiers/Universidad Nacional de Educación a Distancia de Madrid, Lisboa/Madrid, 2009. 
SOARES, C. L. et al. Metodologia do ensino de educação física. São Paulo: Cortez, 1992.

TOSCHI, M. S. (Org.). Leitura na tela: da mesmice à inovação. Goiânia: Ed. PUC Goiás, 2010.

VASCONCELOS, C. dos S. Coordenação do trabalho pedagógico: do projeto político-pedagógico ao cotidiano da sala de aula. 5. ed. São Paulo: Libertad, 2004.

VEEN, W.; VRAKKING, B. Homo zappiens: educando na era digital. Tradução de Vinicius Figueira. Porto Alegre: Artmed, 2009.

ZOBOLI, F; SILVA, R. I. da. Cibercultura e educação física: algumas consideraçóes ontológicas. Motrivivência, n. 34, jun. p. 106-121, 2010. Disponível em: <http://www.periodicos.ufsc.br/index.php/motrivivencia/ article/view/17147/15846>. Acesso em: 12 dez. 2010.

Recebido em: 18 abr. 2012

Aceito em: 1 ago. 2012 